JPE 11-4-22

\title{
High-Efficiency Power Conditioning System for Grid-Connected Photovoltaic Modules
}

\author{
Woo-Young Choi ${ }^{\dagger}$ and Jae-Yeon Choi* \\ $\dagger *$ Division of Electronic Engineering, Chonbuk National University, Jeonju, Korea
}

\begin{abstract}
This paper presents a high-efficiency power conditioning system (PCS) for grid-connected photovoltaic (PV) modules. The proposed PCS consists of a step-up DC-DC converter and a single-phase DC-AC inverter for the grid-connected PV modules. A soft-switching step-up DC-DC converter is proposed to generate a high DC-link voltage from the low PV module voltage with a high-efficiency. A DC-link voltage controller is presented for constant DC-link voltage regulation. A half-bridge inverter is used for the single-phase DC-AC inverter for grid connection. A grid current controller is suggested to supply PV electrical power to the power grid with a unity power factor. Experimental results are obtained from a $180 \mathrm{~W}$ grid-connected PV module system using the proposed PCS. The proposed PCS achieves a high power efficiency of $93.0 \%$ with an unity power factor for a $60 \mathrm{~Hz}$ / 120 Vrms AC power grid.
\end{abstract}

Key Words: Photovoltaic, Power conditioning system, Power-efficiency, Power-factor, Step-up DC-DC converter

\section{INTRODUCTION}

The grid-connected photovoltaic (PV) system is an important technology for future renewable energy applications [1]. It requires a high-efficiency grid-connected PV power conditioning system (PCS) that delivers power to the grid with a low total harmonic distortion (THD) and a high power factor (PF) [2]. Among the various kinds of grid-connected PV PCSs [3], grid-connected PV modules [4] are gaining popularity due to their ability to make grid-connected PV systems more expandable. Because the output terminal of a grid-connected PV module is connected to the power grid, the flexibility of the PV generation system can be greatly improved. Furthermore, the modular concept is expected to reduce the cost of the gridconnected PV system because of the effect of mass production [5].

Fig. 1 shows the typical configuration of a PCS for a gridconnected PV module. The PCS consists of a step-up DCDC converter and a single-phase DC-AC inverter. The step-up DC-DC converter converts the low PV module voltage into a high DC-link voltage. The single-phase DC-AC inverter is connected to the power grid, for the purpose of supplying the electrical power to the grid. For the step-up DC-DC converter of a PCS, the flyback converter has been widely used due to its simple circuit structure [6], [7]. However, the flyback converter suffers from high switching power losses due to its hard-switching operation. The increased voltage stresses of the

\footnotetext{
Manuscript received Feb. 26, 2011; revised Apr. 17, 2011

Recommended for publication by Associate Editor Yujin Song.

$\dagger$ Corresponding Author: wychoi@jbnu.ac.kr

Tel: +82-63-270-4218, Fax: +82-63-270-2394, Chonbuk Nat'l University

* Division of Electronic Engineering, Chonbuk National University, Korea
}

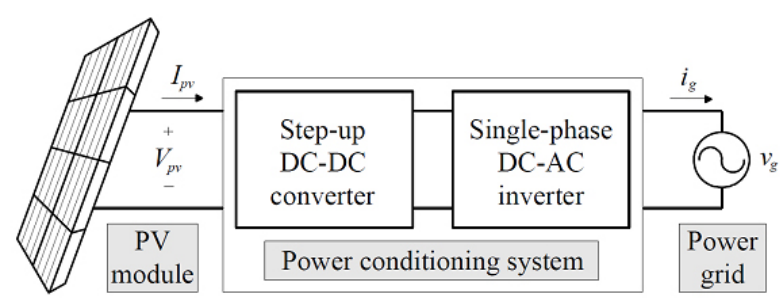

Fig. 1. Configuration of the PCS for the grid-connected PV module.

switching power devices cause high switching power losses, which results in low efficiency of the PCS [8]. Recently, a full-bridge converter has been utilized for the step-up DC-DC converter of grid-connected PV modules [9], [10]. It has low switching power losses due to the soft-switching operation of the switching power devices. However, a lot of active switching power devices and their associated control circuits are required for soft-switching operation. Eventually, the cost of the PCS increases, which limits the practical design of the grid-connected PV module.

This paper presents a high-efficiency PCS for gridconnected PV modules. Fig. 2 shows the circuit diagram of the proposed PCS. A high-efficiency step-up DC-DC converter is proposed in order to increase the power efficiency with a low-cost. It converts the low PV module voltage with a high step-up voltage conversion ratio. The voltage stresses of the output diodes are always clamped to the DC-link voltage without any increases in the voltage stresses. The output diode is turned off under the zero-current switching (ZCS) condition without using any active switching power switches. A DClink voltage controller is also presented for constant DC-link voltage regulation. A half-bridge inverter is used for the single- 


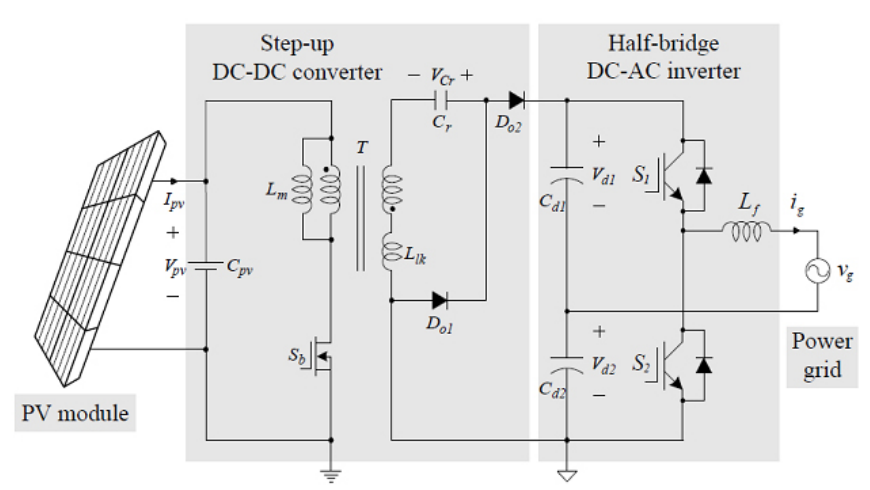

Fig. 2. Circuit diagram of the proposed PCS.

phase DC-AC inverter for the grid connection. A grid current controller is suggested to supply the PV electrical power to the power grid with a unity power factor. Experimental results from a $180 \mathrm{~W}$ grid-connected PV module system using the proposed PCS are discussed. The proposed PCS achieves a high power efficiency of $93.0 \%$ with an unity power factor for a $60 \mathrm{~Hz} / 120 V_{r m s}$ AC power grid.

\section{SYSTEM DESCRIPTION}

Fig. 2 shows a circuit diagram of the proposed PCS. The proposed PCS consists of a step-up DC-DC converter and a half-bridge DC-AC inverter. The step-up DC-DC converter regulates the DC-link voltage $V_{d}\left(=V_{d 1}+V_{d 2}\right)$ as a constant voltage source. The switch $S_{b}$ is a metal-oxide semiconductor field-effect transistor (MOSFET). $D_{o 1}$ and $D_{o 2}$ are the output diodes, respectively. The step-up DC-DC converter is controlled at a constant switching frequency $T_{s}\left(=1 / f_{s}\right)$ with pulse width modulation (PWM). The half-bridge inverter supplies power to the grid. The switches $S_{1}$ and $S_{2}$ are insulated gate bipolar transistors (IGBTs). The half-bridge inverter is controlled at a constant switching frequency $T_{i}\left(=1 / f_{i}\right)$ with sinusoidal PWM.

Fig. 3(a) shows the operation modes of the proposed stepup DC-DC converter for $T_{s}$. The transformer $T$ is modeled as an ideal transformer with a turns ratio of $1: N$ where $N=N_{p} / N_{s}$. It has a magnetizing inductor $L_{m}$ with a leakage inductor $L_{l k}$. The proposed converter operates in continuous conduction mode so that the magnetizing inductor current $i_{L m}$ flows continuously. The capacitor $C_{d}$ is modeled as an equivalent capacitor as $C_{d}=\left(C_{d 1} C_{d 2}\right) /\left(C_{d 1}+C_{d 2}\right)$. The capacitors $C_{p v}, C_{r}$, and $C_{d}$ are large enough so that their voltages are considered constant as $V_{p v}, V_{c r}$, and $V_{d}$. Fig. 3(b) shows operation waveforms of the converter for $T_{s}$. $D_{c}$ is the duty ratio based on a $S_{b}$ turn-on time. The proposed converter has three distinct operating modes for $T_{s}$ as follows:

Mode $1\left[t_{0}, t_{1}\right]$ : At $t=t_{0}, S_{b}$ is turned on. The voltage across $L_{m}$ is $V_{p v}$. A current path including $L_{l k}, D_{o 1}, C_{r}$, and the secondary winding of $T$ is formed on the DC-link capacitor side. The diode current $i_{D o 1}$ flows as:

$$
i_{D o 1}(t)=\frac{N V_{p v}+V_{c r}}{\sqrt{L_{l k} / C_{r}}} \sin \left(\omega_{r}\left(t-t_{0}\right)\right)
$$
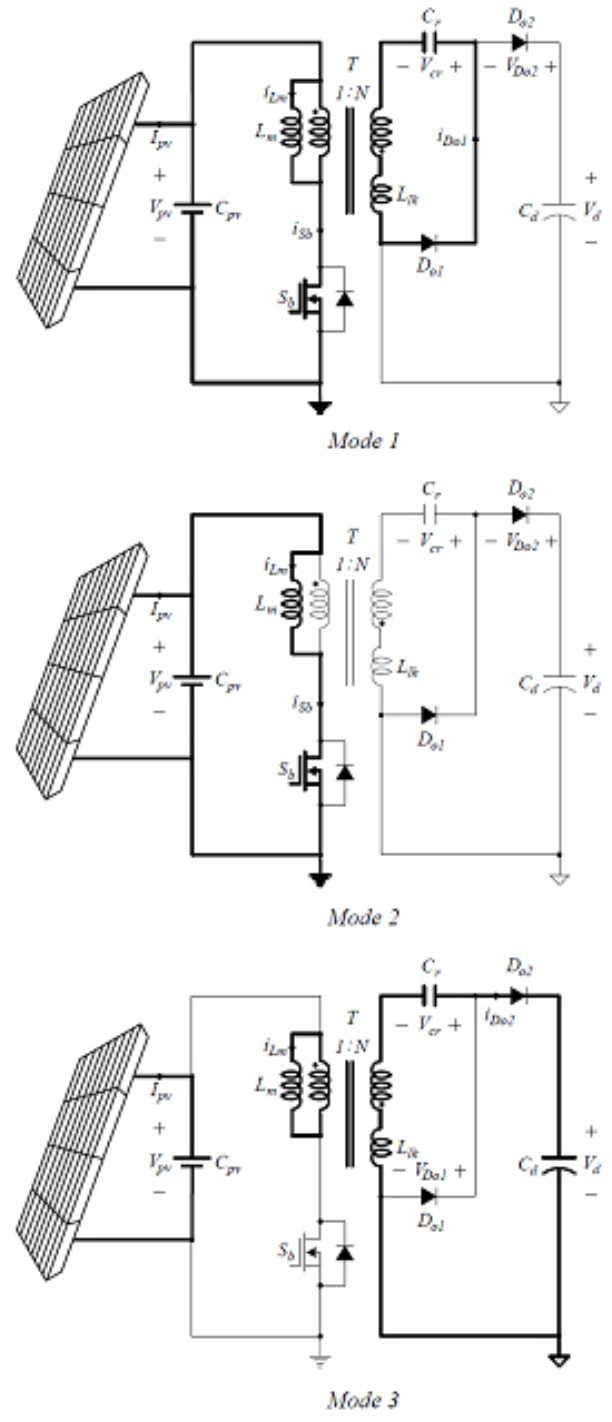

(a)

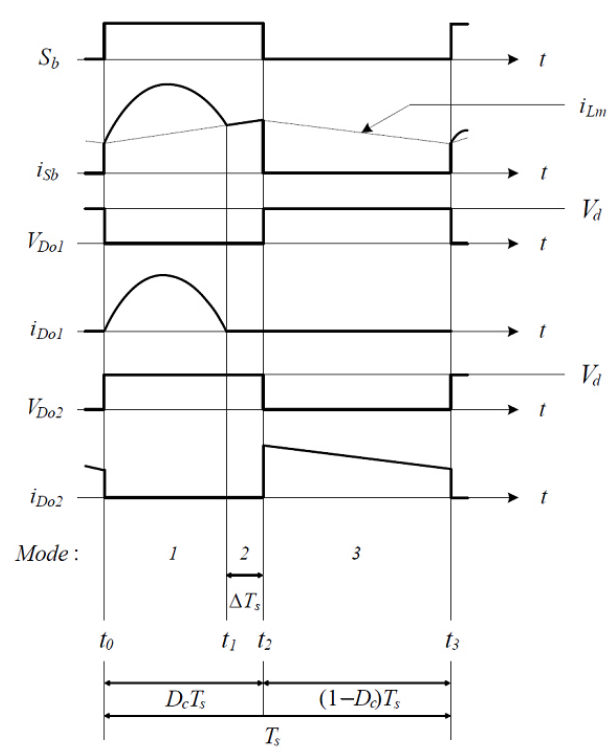

(b)

Fig. 3. Operation of the step-up DC-DC converter for $T_{s}$. (a) Operation modes, (b) operation waveforms. 
where the angular resonant frequency $\omega_{r}$ is given by:

$$
\omega_{r}=\frac{1}{\sqrt{L_{l k} C_{r}}} .
$$

The magnetizing current $i_{L m}$ and the switch current $i_{S b}$ are expressed as:

$$
\begin{aligned}
i_{L m}(t) & =i_{L m}\left(t_{0}\right)+\frac{V_{p v}}{L_{m}}\left(t-t_{0}\right) \\
i_{S b}(t) & =i_{L m}(t)+N i_{D o 1}(t) .
\end{aligned}
$$

Mode 2 [ $t 1, t 2]$ : At $t=t_{1}$, the half resonant period of $i_{D o 1}$ is finished. Because $i_{D o 1}$ is zero at $t=t_{1}$, the output diode $D_{o 1}$ is turned off at zero-current. On the PV module side, the magnetizing current $i_{L m}$ increases linearly as in Mode 1.

Mode 3 [t2, t3]: At $t=t_{2}, S_{b}$ is turned off. $D_{o 2}$ is turned on, entering into a conduction state. Since the reverse-voltage across $D_{o 1}$ is $V_{d}$, the voltage across the secondary winding of $T$ is $V_{d}-V_{c r}$. On the DC-link capacitor side, a current path including $C_{r}, D_{o 2}, C_{d}, L_{l k}$, and the secondary windings of $T$ is formed. Then, the energy stored in the capacitor $C_{r}$ is transferred to the capacitor $C_{d}$. The diode current $i_{D o 2}$ decreases linearly as:

$$
i_{D o 2}(t)=\frac{i_{L m}\left(t_{2}\right)}{N}-\frac{V_{d}-V_{c r}}{N^{2} L_{m}+L_{l k}}\left(t-t_{2}\right) .
$$

The magnetizing current $i_{L m}$ is expressed as:

$$
i_{L m}(t)=i_{L m}\left(t_{2}\right)-\frac{V_{d}-V_{c r}}{N L_{m}}\left(t-t_{2}\right) .
$$

The next switching period begins when $S_{b}$ is turned on at $t=t_{3}$. By the voltage-second balance relation on the secondary side of $T$ for $T_{s}$ :

$$
D_{c} V_{c r}=\left(V_{d}-V_{c r}\right)\left(1-D_{c}\right) .
$$

By simplifying (7):

$$
V_{c r}=\left(1-D_{c}\right) V_{d} .
$$

By the voltage-second balance relation on the primary side of $T$ for $T_{s}$ :

$$
N D_{c} V_{p v}=D_{c}\left(1-D_{c}\right) V_{d}
$$

By simplifying (9):

$$
\frac{V_{d}}{V_{p v}}=\frac{N}{\left(1-D_{c}\right)} .
$$

Supposed that the average magnetizing current $i_{L m}$ is the average DC-link capacitor current $I_{d}$ during $T_{s}$, the following relation is given by:

$$
\frac{i_{L m}\left(t_{0}\right)+i_{L m}\left(t_{2}\right)}{2}=N I_{d} .
$$

By (3) and (11), the currents $i_{L m}\left(t_{0}\right)$ and $i_{L m}\left(t_{2}\right)$ can be expressed as:

$$
\begin{aligned}
& i_{L m}\left(t_{0}\right)=N I_{d}-\frac{V_{p v} D_{c} T_{s}}{2 L_{m}} \\
& i_{L m}\left(t_{2}\right)=N I_{d}+\frac{V_{p v} D_{c} T_{s}}{2 L_{m}} .
\end{aligned}
$$

The existence of Mode 2 ensures the ZCS turn-off of $D_{o 1}$. Since the interval of Mode 2 can be changed by the angular

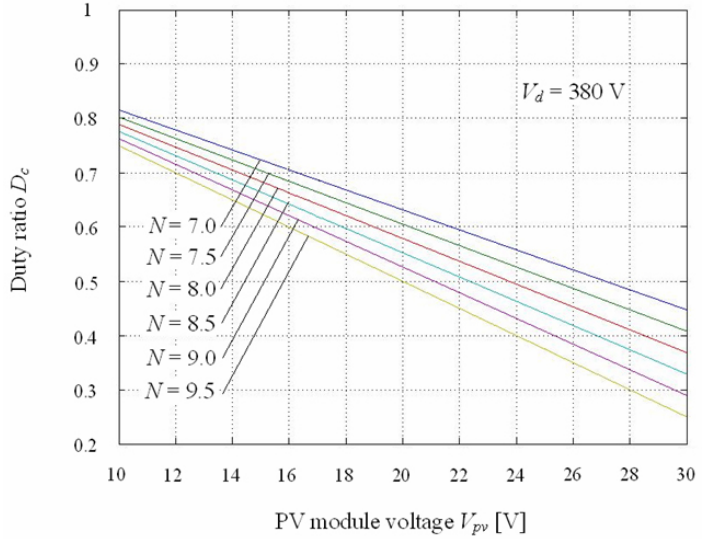

Fig. 4. Relation between the DC-link voltage $V_{d}$ and the duty ratio $D_{c}$ according to different values of the turns ratio $N$.

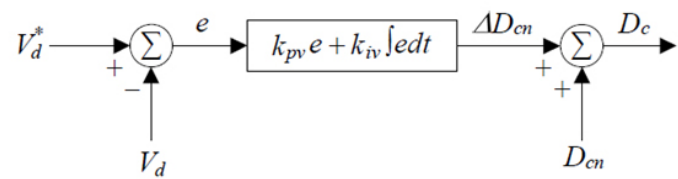

Fig. 5. DC-link voltage control diagram of the step-up DC-DC converter.

resonant frequency $\omega_{r}$, the critical condition for the ZCS turnoff of $D_{o 1}$ is $i_{L m}\left(D_{c} T_{s}\right)=N i_{D o 1}\left(D_{c} T_{s}\right)$ at $\Delta T_{s}=0$. Then, the angular resonant frequency $\omega_{r}$ should satisfy the following condition as:

$$
\omega_{r}=\frac{1}{\sqrt{L_{l k} C_{r}}}>\omega_{r c}
$$

where the critical angular resonant frequency $\omega_{r c}=2 \pi f_{r c}$ is determined by:

$$
I_{d}=\left(1-D_{c}\right) V_{d}\left(\frac{2 \sin \left(\omega_{r c} D_{c} T_{s}\right)}{\sqrt{L_{l k} / C_{r}}}-\frac{D_{c} T_{s}}{2 N^{2} L_{m}}\right)
$$

where $f_{r c}$ is the critical resonant frequency.

\section{SySTEM CONTROL}

\section{A. DC-Link Voltage Controller}

The proposed step-up DC-DC converter has a high step-up voltage conversion ratio, as shown in (10). Fig. 4 shows the relationship between the duty ratio $D_{c}$ and the PV module voltage $V_{p v}$ for a constant DC-link voltage $\left(V_{d}=380 \mathrm{~V}\right)$. The duty ratio $D_{c}$ should be controlled for constant DC-link voltage regulation of the PV module voltage.

Fig. 5 shows a DC-link voltage control diagram of the stepup DC-DC converter. The duty ratio $D_{c}$ of $S_{b}$ is determined by adding an additional duty ratio $\Delta D_{c n}$ to the nominal duty ratio $D_{c n}$. From (10), the nominal duty ratio $D_{c n}$ is:

$$
D_{c n}=1-\frac{N V_{p v}}{V_{d}}
$$

The additional duty ratio $\Delta D_{c n}$ is given by:

$$
\Delta D_{c n}=k_{p v} e+k_{i v} \int e d t
$$

where $e$ is $V_{d}^{*}-V_{d} . V_{d}^{*}$ is the reference DC-link voltage. $k_{p v}$ and $k_{i v}$ are the proportional and integral gains, respectively. 


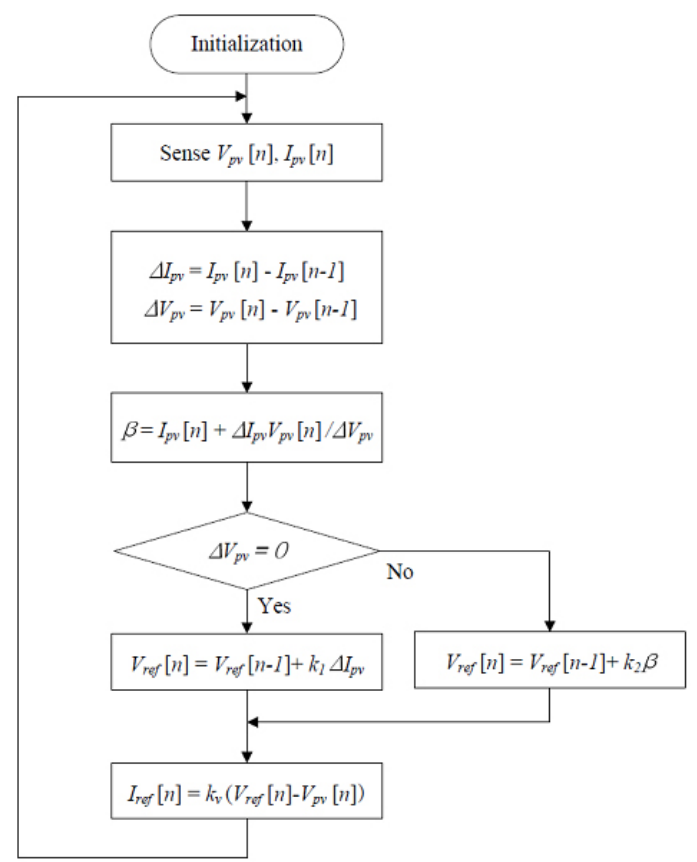

Fig. 6. Flowchart of the MPPT control.

\section{B. Maximum Power Point Tracking Controller}

In order to extract the maximum electrical power from the PV module, maximum power point tracking (MPPT) should be implemented. For the MPPT of a PV module, various MPPT techniques have been developed [11]-[13]. Among them, the modified incremental conductance method [13] is employed for the MPPT of the proposed PCS. Fig. 6 shows a flowchart of the MPPT control. The power generated from the PV module is:

$$
P_{p v}=V_{p v} I_{p v} .
$$

The power slope $\beta=d P_{p v} / d V_{p v}$ of the PV module can be expressed as:

$$
\beta=I_{p v}+\frac{\Delta I_{p v}}{\Delta V_{p v}} V_{p v}
$$

where $\Delta I_{p v}$ and $\Delta V_{p v}$ are the increments of the PV module voltage and current, respectively. When $\beta<0$, decreasing the voltage reference $V_{\text {ref }}$ forces $\beta$ to approach zero; when $\beta>0$, increasing $V_{r e f}$ forces $\beta$ to approach zero; and when $\beta=0$, $V_{\text {ref }}$ does not need any change. When increasing or decreasing $V_{r e f}$, the smooth transition to the MPP can be achieved by applying the following proportional control with respect to the power slope $\beta$ as:

$$
V_{r e f, n}= \begin{cases}V_{r e f, n-1}+k_{1} \Delta I_{p v}, & \text { for } \Delta V_{p v}=0 \\ V_{r e f, n-1}+k_{2} \beta, & \text { for } \Delta V_{p v} \neq 0\end{cases}
$$

where $k_{1}$ and $k_{2}$ are the proportional gains. In the case where $\Delta V_{p v}=0$, the voltage reference $V_{r e f}$ is proportionally compensated according to the current increment $\Delta I_{p v}$. Increasing the PV module current $I_{p v}$ decreases the PV module voltage $V_{p v}$. Decreasing the PV module current $I_{p v}$ increases the PV module voltage $V_{p v}$. Thus, the current reference $I_{r e f}$ for the PV module current control is determined by the following controller as:

$$
I_{r e f}=k_{v}\left(V_{r e f}-V_{p v}\right)
$$

where $k_{v}$ is the proportional gain.

\section{Grid Current Controller}

The proposed PCS supplies power to the grid by a halfbridge inverter. To achieve an unity PF, the grid current $i_{g}$ should be controlled in phase with the grid voltage $v_{g}$ which is given by:

$$
v_{g}=\sqrt{2} V_{g} \sin \omega t
$$

where $v_{g}$ is the root-mean-squared value of the grid voltage $v_{g} . \omega$ is the frequency of $v_{g}$. Each switch is controlled in a complimentary manner, generating sinusoidal PWM pulses. $S_{1}$ is controlled when $v_{g}$ is in the positive half-period. When $S_{1}$ is turned on in the positive half-period, $V_{d} / 2$ is applied across the output filter inductor $L_{f}$. The grid current $i_{g}$ increases linearly. The voltage across $L_{f}$ is expressed as:

$$
L_{f} \frac{d i_{g}}{d t}=\frac{V_{d}}{2}-v_{g} .
$$

On the other hand, when $S_{2}$ is turned on in the positive half-period, $-V_{d} / 2$ is applied across $L_{f}$. The grid current $i_{g}$ decreases linearly. The voltage across $L_{f}$ is expressed as:

$$
L_{f} \frac{d i_{g}}{d t}=-\frac{V_{d}}{2}-v_{g} .
$$

Depending on the duty ratio $D_{i}$ of $S_{1}$, the average voltage of $L_{f}$ during $T_{i}$ is given with the following current deviation $\Delta i_{g}$ as:

$$
L_{f} \frac{\Delta i_{g}}{T_{i}}=\left(\frac{V_{d}}{2}-v_{g}\right) D_{i}+\left(-\frac{V_{d}}{2}-v_{g}\right)\left(1-D_{i}\right) .
$$

In the negative half period, the following relation can be obtained for the duty ratio $D_{i}$ of $S_{2}$ as:

$$
L_{f} \frac{\Delta i_{g}}{T_{i}}=\left(-\frac{V_{d}}{2}-v_{g}\right) D_{i}+\left(\frac{V_{d}}{2}-v_{g}\right)\left(1-D_{i}\right) .
$$

Let the duty ratio $D_{i}$ be expressed as:

$$
D_{i}=D_{\text {in }}+\Delta D_{\text {in }}
$$

where $D_{\text {in }}$ is the nominal duty ratio, and $\Delta D_{\text {in }}$ is a perturbed duty ratio. From (25)-(27), the nominal duty ratio $D_{i n}$ and the perturbed duty ratio $\Delta D_{\text {in }}$ can be expressed as:

$$
\begin{gathered}
D_{\text {in }}=\frac{1}{2}+\frac{\left|v_{g}\right|}{V_{d}} \\
\Delta D_{\text {in }}=\frac{L_{f} \Delta\left|i_{g}\right|}{V_{d} T_{i}} .
\end{gathered}
$$

To make the grid current $i_{g}$ track its current reference $i_{g}^{*}$, the following proportional current control is used as:

$$
\Delta D_{\text {in }}=k_{c}\left(\left|i_{g}^{*}\right|-\left|i_{g}\right|\right)
$$

where $k_{c}$ is the proportional gain. The current reference $i_{g}^{*}$ is defined as $i_{g}^{*}=i_{g} \sin \omega t$, where the peak magnitude $I_{g}$ is generated by the following proportional-integral (PI) current controller as:

$$
I_{g}=k_{p c}\left(I_{r e f}-I_{p v}\right)+k_{i c} \int\left(I_{r e f}-I_{p v}\right) d t
$$




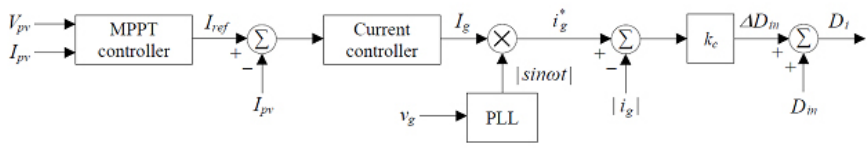

Fig. 7. Grid current control diagram of the half-bridge DC-AC inverter.

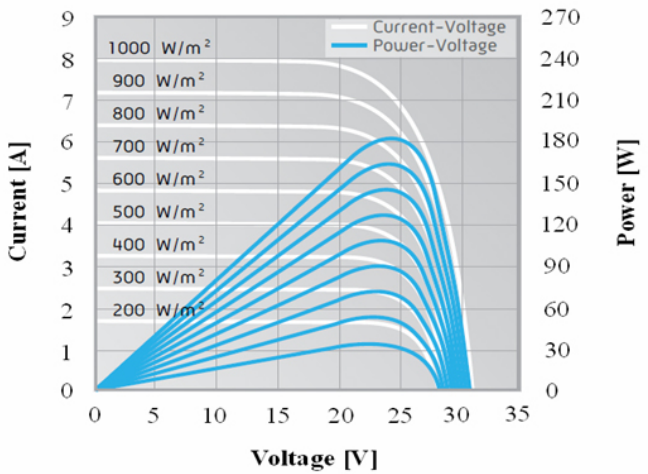

Fig. 8. Electrical characteristics of the PV module.

where $k_{p c}$ and $k_{i c}$ are the proportional and integral gains, respectively. Fig. 7 shows a control block diagram of the grid current controller. The current reference $I_{r e f}$ is generated from the MPPT controller. A phase-locked loop (PLL) is used for grid synchronization by employing the zero-crossing edge detection method [14]. The output $\Delta D_{\text {in }}$ of the current controller only generates the inductor voltage drop required to maintain the sinusoidal grid current. With the addition of the nominal duty $D_{i n}$ to the original nonlinear dynamic system (25) and (26), the relation between $\Delta D_{i n}$ and $\left|i_{g}\right|$ in (29) becomes a first-order linear dynamic system. The addition of the nominal duty $D_{i n}$ relaxes the burden of the grid current control and improves the grid current waveform.

\section{EXPERIMENTAL RESULTS}

To evaluate the performance of the proposed PCS, a $180 \mathrm{~W}$ prototype of a grid-connected PV module system has been built. Fig. 8 shows the electrical characteristics of the PV module (MITSUBISHI ELECTRIC, PV-UD180MF5) used for the test of the prototype. It has the maximum power of 180 $\mathrm{W}$ at a PV module voltage of $24.2 \mathrm{~V}$. The hardware circuit of the PCS is divided into two parts: the microcontroller-based control circuit and the power circuit.

Fig. 9 shows an overall control diagram of the PCS. It is implemented fully in software using a single-chip microcontroller (Microchip, dsPIC30F3011). The voltage and current controllers are performed in every $100 \mu$ s period. The MPPT controller is performed in every $100 \mathrm{~ms}$ period. Table I shows the major system parameters for the power circuits of the PCS. The step-up DC-DC converter operates at a $50 \mathrm{kHz}$ switching frequency to generate a $380 \mathrm{~V}$ DC-link voltage. The transformer $T$ is implemented by using a PQ3230 core with 3 turns for the primary winding and 21 turns for the secondary winding. The magnetizing inductor $L_{m}=20 \mu \mathrm{H}$ is realized with a $0.7-\mathrm{mm}$ air-gap, which results in a leakage inductor $L_{l k}=0.3 \mu \mathrm{H}$. The critical resonant frequency is determined as $f_{r c}=65 \mathrm{kHz}$ with the parameters $L_{l k}=0.3 \mu \mathrm{H}$ and $C_{r}=20 \mu \mathrm{F}$.

Fig. 10 shows the experimental waveforms of the step-up DC-DC converter at a PV module voltage of $24.2 \mathrm{~V}$ for the

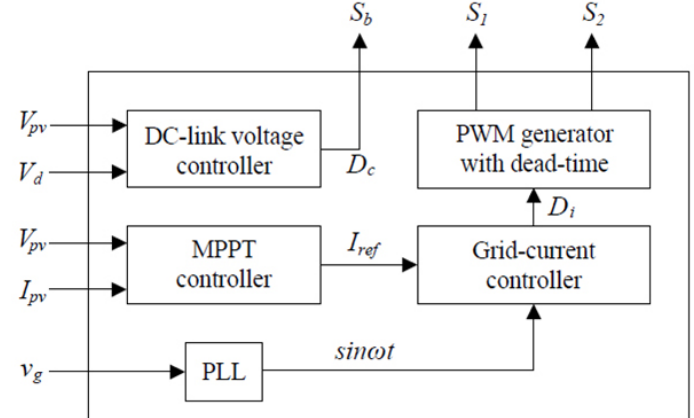

Fig. 9. Overall control diagram of the PCS.

TABLE I

MAJOR CIRCUIT PARAMETERS

\begin{tabular}{|cc|}
\hline System parameters & Value \\
\hline PV module voltage $V_{p v}$ & $15 \mathrm{~V} \sim 30 \mathrm{~V}$ \\
\hline DC-link voltage $V_{d}$ & $380 \mathrm{~V}$ \\
\hline Grid voltage $v_{g}$ & $60 \mathrm{~Hz} / 120 \mathrm{~V}_{\mathrm{ac}}$ \\
\hline $\begin{array}{c}\text { DC-DC converter switching } \\
\text { frequency } f_{s}\end{array}$ & $50 \mathrm{kHz}$ \\
\hline $\begin{array}{c}\text { DC-AC inverter switching } \\
\text { frequency } f_{i}\end{array}$ & $20 \mathrm{kHz}$ \\
\hline Input filter capacitor $C_{p v}$ & $6600 \mu \mathrm{F}$ \\
\hline DC-link capacitor $C_{d 1}, C_{d 2}$ & $220 \mu \mathrm{F}$ \\
\hline Transformer turns ratio $N$ & $N=7\left(N_{p}=3, N_{s}=21\right)$ \\
\hline Magnetizing inductor $L_{m}$ & $20 \mu \mathrm{H}$ \\
\hline Leakage inductor $L_{l k}$ & $0.3 \mu \mathrm{H}$ \\
\hline Resonant capacitor $C_{r}$ & $20 \mu \mathrm{H}$ \\
\hline Output filter inductor $L_{f}$ & $1 \mu \mathrm{mH}$ \\
\hline MOSFET $S_{b}$ & FDMC86102 $(100 \mathrm{~V} / 20 \mathrm{~A})$ \\
\hline IGBT $S_{1}, S_{2}$ & FGP5060LS $(600 \mathrm{~V} / 5 \mathrm{~A})$ \\
\hline Diode $D_{o 1}, D_{o 2}$ & \\
\hline
\end{tabular}

maximum PV module power of $180 \mathrm{~W}$. The output diode $D_{o 1}$ is turned off under zero-current after the half resonant period of $i_{D o 1}$. ZCS turn-off of $D_{o 1}$ is achieved, which minimizes the switching power losses. The voltages $V_{D o 1}$ and $V_{D o 2}$ become the DC-link voltage $V_{d}$ without any increases in voltage stress. Fig. 11 shows the measured waveforms of the grid voltage $v_{g}$ and grid current $i_{g}$ at $180 \mathrm{~W}$. The grid current $i_{g}$ is sinusoidal and in phase with the grid voltage $v_{g}$. The measured PF is 0.99 . The measured THD is $3.6 \%$.

Fig. 12 shows the DC-link voltage $V_{d}$ and grid current $i_{g}$ when the input PV power changes from $90 \mathrm{~W}$ to $180 \mathrm{~W}$ abruptly. It can be seen that the DC-link voltage is tightly regulated with little overshoot due to the abrupt PV power variation.

In order to demonstrate the improved efficiency of the proposed PCS, the conventional one in [6] has been designed and tested in the laboratory. The conventional system consisting of a flyback DC-DC converter and a full-bridge DC-AC inverter has been built. Fig. 13 shows the measured power efficiencies of the proposed step-up DC-DC converter and the flyback converter from [6]. The flyback converter has been designed to generate $380 \mathrm{~V}$ of DC-link voltage from the same PV module voltage. The power efficiency is measured by a YOKOGAWA WT120, as a digital power meter, is used for calculating the power efficiency. For the maximum power of $180 \mathrm{~W}$, the power efficiency of the flyback converter is $95.3 \%$. On the other hand, the proposed DC-DC converter achieves a power efficiency of $96.0 \%$ at $180 \mathrm{~W}$. The proposed converter improves power efficiency by reducing the switching power 


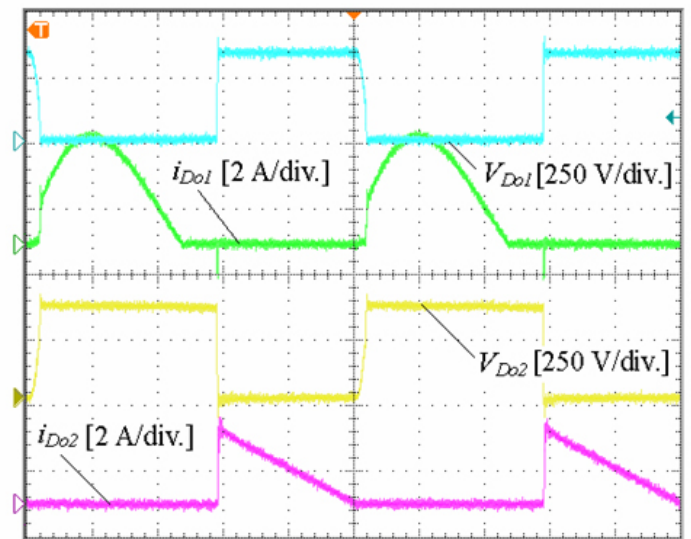

time $[4 \mu \mathrm{s} / \mathrm{div}$.

Fig. 10. Experimental waveforms of the DC-DC converter: output diode voltages $V_{d o 1}$ and $V_{d o 2}$ and output diode currents $i_{d o 1}$ and $i_{d o 2}$.

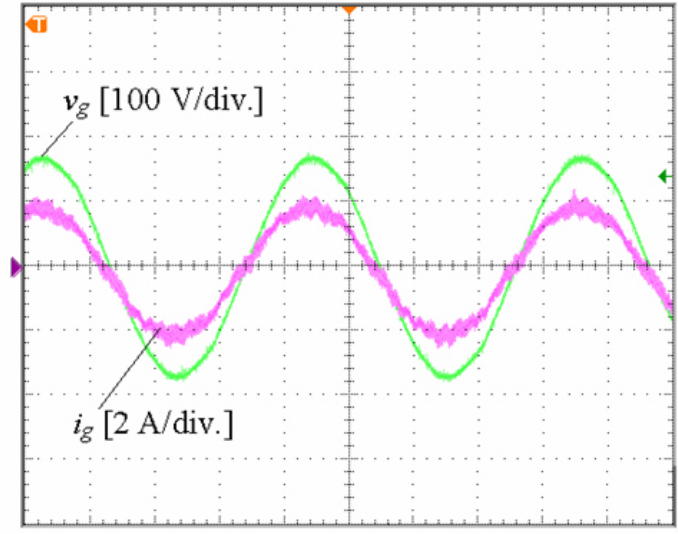

time $[4 \mathrm{~ms} /$ div.]

Fig. 11. Experimental waveforms of the DC-AC inverter: grid voltage $v_{g}$ and grid current $i_{g}$.

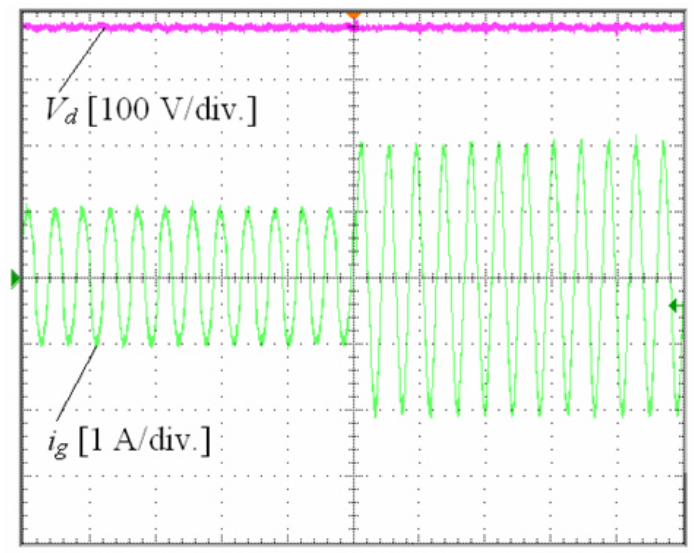

time $[40 \mathrm{~ms} / \mathrm{div}$.

Fig. 12. Experimental waveforms of the PCS: DC-link voltage $V_{d}$ and grid current $i_{g}$ for the PV power variation.

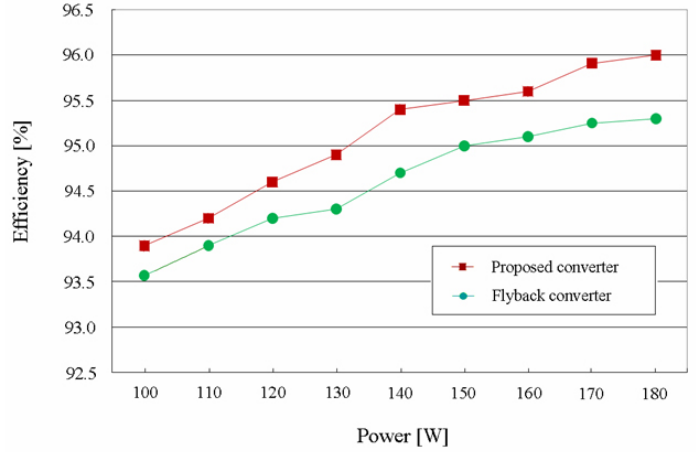

Fig. 13. Measured efficiencies of the proposed DC-DC converter and efficiencies of the conventional converter.

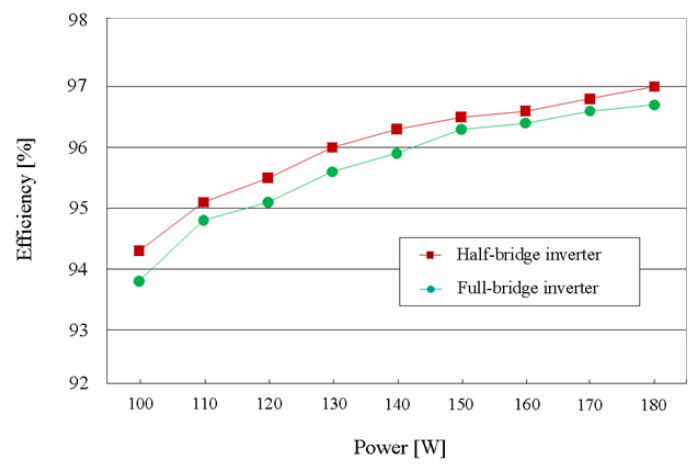

Fig. 14. Measured efficiencies of the half-bridge inverter and efficiencies of the full-bridge inverter in the PCS.

losses. Specifically, by achieving ZCS of the output diode, the proposed DC-DC converter reduces the output diode reverserecovery losses to generate a high DC-link voltage of around $380 \mathrm{~V}$.

Fig. 14 shows the efficiency of the half-bridge DC-AC inverter in the proposed PCS when the PCS is applied to a $120 \mathrm{Vrms}$ AC power grid. It also shows the efficiency of the full-bridge DC-AC inverter in the conventional PCS from [6] when the PCS is applied to a 120 Vrms AC power grid. The power efficiency was calculated by measuring the DC-link power and the AC output power in the PCS. The half-bridge inverter achieves an efficiency of $97.0 \%$ for $180 \mathrm{~W}$. On the other hand, the full-bridge inverter achieves an efficiency of $96.7 \%$ for $180 \mathrm{~W}$. The power efficiency is improved by 0.3 $\%$. The switching power losses are reduced by employing a half-bridge inverter to generate a $120 V_{r m s}$ AC output voltage. The efficiency of the PCS for a $230 V_{r m s}$ AC power grid can be obtained by using a full-bridge DC-AC inverter for the proposed PCS. It has also been tested in the laboratory, achieving a power efficiency of $92.7 \%$ for the entire PCS including the DC-DC converter and the DC-AC inverter for a $180 \mathrm{~W}$ output power.

Fig. 15 compares the efficiency of the proposed PCS to the efficiency of the conventional one from [6]. The proposed PCS, consisting of the proposed DC-DC converter and the half-bridge inverter, achieves an efficiency of $93.0 \%$ for 180 W. On the other hand, the conventional system, consisting of a flyback converter and a full-bridge inverter, achieves 92.1 $\%$ for $180 \mathrm{~W}$. Both systems employ two power conversion stages including a DC-DC converter and a DC-AC inverter. 


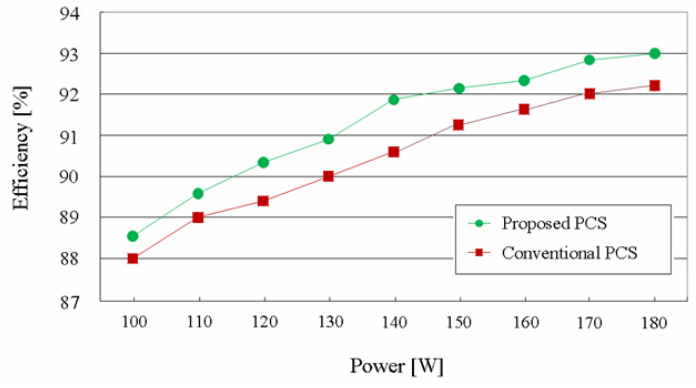

Fig. 15. Measured efficiencies of the proposed PCS and efficiencies of the conventional PCS.

Compared to the conventional system, the proposed PCS improves the total power conversion efficiency by increasing the efficiency of the DC-DC converter part and also by increasing the efficiency of the DC-AC inverter part.

\section{CONCLUSions}

This paper proposes a high-efficiency PCS for gridconnected PV modules. The proposed PCS consists of a highefficiency step-up DC-DC converter and a single-phase halfbridge inverter. A high-efficiency step-up DC-DC converter has been proposed to increase power conversion efficiency at a low-cost. It has desirable features such as a simple power circuit, low switching power losses, and a high step-up voltage conversion ratio. DC-link voltage and grid current controllers have been suggested for the control strategy of the proposed PCS. A prototype of the PCS has been built and tested for a $180 \mathrm{~W}$ grid-connected PV module. Experimental results have shown that the proposed PCS achieves a high efficiency of $93.0 \%$ with an unity power factor for a $60 \mathrm{~Hz} / 120 V_{r m s} \mathrm{AC}$ power grid.

\section{ACKNOWLEDGMENT}

This paper was supported by research funds of Chonbuk National University in 2010. Also, this work was supported by National Research Foundation of Korea (NRF) grant funded by the Korea government (MEST) (2010-0029431).

\section{REFERENCES}

[1] B. D. Min, J. P. Lee, J. H. Kim, T. J. Kim, D. W. Yoo, K. R. Ryu, J. J. Kim, and E. H. Song, "A novel grid-connected PV PCS with new high efficiency converter," Journal of Power Electronics, Vol. 8, No. 4, pp. 309-316, Oct. 2008

[2] M. Aiello, A. Cataliotti, S. Favuzza, and G. Graditi, "Theoretical and experimental comparison of total harmonic distortion factors for the evaluation of harmonic and interharmonic pollution of grid-connected photovoltaic systems," IEEE Trans. Power Delivery, Vol. 21, No. 3, pp. 1390-1397, Jul. 2006
[3] S. B. Kjaer, J. K. Pedersen, and F. Blaabjerg, "A review of single-phase grid-connected inverters for photovoltaic modules," IEEE Trans. Industry Applications, Vol. 41, No. 5, pp. 1292-1306, Sep. 2005.

[4] Q. Li and P. Wolfs, "A review of the single phase photovoltaic module integrated converter topologies with three different DC link configurations," IEEE Trans. Power Electronics, Vol. 23, No. 3, pp. 1320-1333, May 2008.

[5] L. Zhang, K. Sun, Y. Xing, L. Feng, and H. Ge, "A modular gridconnected photovoltaic generation system based on DC bus," IEEE Trans. Power Electronics, Vol. 26, No. 2, pp. 523-531, May 2011.

[6] D. C. Martins, and R. Demonti, "Grid-connected PV system using two energy processing stages," in Proc. IEEE Photovoltaic Specialists Conference, pp. 1649-1652, 2002.

[7] S. Saha and V. P. Sundarsingh, "Novel grid-connected photovoltaic inverter," in Proc. IEE Gener. Transm. Distrib., Vol. 143, No. 2, pp. 219-224, 1996.

[8] F. Chan and H. Calleja, "Design strategy to optimize the reliability of grid-connected PV systems," IEEE Trans. Ind. Electron., Vol. 56, No. 11 , pp. 4465-4472, Nov. 2009.

[9] C. Rodriguez and G. A. J. Amaratunga, "Long-lifetime power inverter for photovoltaic AC modules," IEEE Trans. Ind. Electron., Vol. 55, No. 7, pp. 2593-2601, Jul. 2008.

[10] M. Cacciato, A. Consoli, R. Attanasio, and F. Gennaro, "Soft-switching converter with HF transformer for grid-connected photovoltaic systems," IEEE Trans. Ind. Electron., Vol. 57, No. 5, pp. 1678-1686, May 2010.

[11] H. S. Bae, J. H. Park, B. H. Cho, and G. J. Yu, "New MPPT control strategy for two-stage grid-connected photovoltaic power conditioning system," Journal of Power Electronics, Vol. 7, No. 2, pp. 174-180, Apr. 2007.

[12] H. E. Park and J. H. Song, "A dP/dV feedback-controlled MPPT method for photovoltaic power system using II-SEPIC," Journal of Power Electronics, Vol. 9, No. 4, pp. 604-611, Jul. 2009.

[13] J. M. Kwon, K. H. Nam, and B. H. Kwon, "Photovoltaic power conditioning system with line connection," IEEE Trans. Ind. Electron., Vol. 53, No. 4, pp. 1048-1054, Aug. 2006.

[14] M. Ciobotaru, V. G. Agelidis, R. Teodorescu, and F. Blaabjerg, "Accurate and less-disturbing active anti-islanding method based on PLL for gridconnected converters," IEEE Trans. Power Electron., Vol. 25, No. 6, pp. 1576-1584, Jun. 2010.

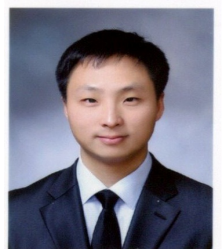

Woo-Young Choi was born in Kwangju, South Korea in 1979. He received his B.S. in Electrical Engineering from Chonnam National University, Kwangju, Korea, in 2004. He received his Ph.D. in Electronic and Electrical Engineering from the Pohang University of Science and Technology (POSTECH), Pohang, Korea, in 2009. From 2009 to 2010, he was a post-doctoral Research Fellow at Virginia Polytechnic Institute and State University (Virginia Tech), U.S.A. Since 2010, he has been with the Division of Electronic Engineering, Chonbuk National University, Jeonju, South Korea, where he is currently a Professor. His current research interests include power converters for high-frequency power conversion, display technology, and renewable energy.

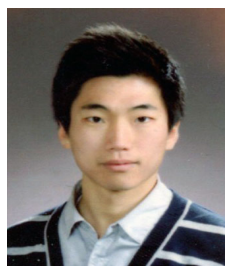

Jae-Yeon Choi was born in South Korea in 1986. He is now studying for his B.S. in Electronics Engineering from Chonbuk National University, Jeonju, Korea. His current research interest includes switching power converters for advanced displays and renewable energy. 